\title{
Effect of catch-up growth after food restriction on the entero-insular axis in rats
}

\author{
Lu-Lu Chen*+, Wei-Hong Yang ${ }^{\dagger}$, Juan Zheng, Xiang Hu, Wen Kong and Hao-Hao Zhang
}

\begin{abstract}
Background: Catch-up growth after food restriction (CUGFR) is characterized by a significant change in food intake which could theoretically lead to the change in glucagon-like peptide-1 (GLP-1) secretion that consequently results in altered functions of pancreatic islets.

Methods: Experimental rats were divided into two groups. Rats in CUGFR group were put on food-restriction for 4 weeks, and then allowed full access to food for 0, 2, 4 weeks respectively while rats in the control group were offered ad libitum access to food. Plasma glucose, insulin and GLP-1 level during OGTT were measured in all the rats. Moreover, morphology of intestinal mucosa, number of $L$ cells, beta cell mass, incretin effect and the expression of GLP-1 receptor (GLP-1R) gene in the islets were also determined.

Results: The size of pancreatic islets, insulin concentration, plasma GLP-1 concentration, incretin effect, villus height-tocrypt depth ratio and $L$ cells were all significantly decreased in CUGFR group at the end of a 4-week food-restriction period as compared with the controls. Insulin concentration and the villus height-to-crypt depth ratio were increased and finally exceeded the level of the control group over a 4-week catch-up period. Nevertheless, at the conclusion of the study, islet size, L cells number, plasma GLP-1 concentration and incretin effect increased but failed to reach the levels of the controls.
\end{abstract}

Conclusion: CUGFR decreases incretin effect and disturbs the entero-insular axis partially by decreasing GLP-1 concentration, which might be responsible for the increased risk of metabolic disorder during CUGFR.

\section{Background}

The term 'catch-up growth' was first introduced by Prader in 1963[1], and following studies have shown that nutritional rehabilitation after malnutrition could motivate catch-up growth, which was characterized by rapid growth following a temporary period of growth retardation[2] and apparent insulin resistance[3]. A relationship between low birth weight and impaired glucose tolerance late in life has been epidemiologically identified[4] and the association between insulin resistance and impaired function of the pancreatic beta cells in adulthood has been confirmed[5]. Because of these findings, the link

* Correspondence: cheria_chen@126.com

1 Department of Endocrinology, Union Hospital, Tongji Medical College, Huazhong University of Science and Technology, Wuhan 430022, China

+ Contributed equally

Full list of author information is available at the end of the article between catch-up growth and later metabolic disorder has become a subject of active investigation[6].

The gastrointestinal tract is a site where the body exchanges energy with the external environment. The individuals who have undergone catch-up growth after food restriction show a significant increase in appetite and food intake during nutritional rehabilitation[7]. The change in the gastrointestinal load will inevitably lead to alteration in the function of gastrointestinal tract.

The concept that intestinal hormones or 'incretins' are involved in the augmentation of insulin secretion in response to oral compared with intravenous glucose is embodied in the classical descriptions of the 'entero-insular' axis[8]. The two major hormones of the entero-insular axis are believed to be glucose-dependent insulinotropic polypeptide (GIP) and glucagon-like peptide-1 (GLP-1)[9], which exert a number of important 
biological effects, including inhibition of glucagons and somatostatin, maintenance of beta cell mass, delay of gastric emptying, and inhibition of feeding[10]. Currently, the control of incretin secretion represents a major goal for new therapeutic as well as nutritional strategies for treating and/or reducing the risk of hyperglycaemic syndromes, excessive body weight and thus improving overall well-being[11].

Both human and animal studies showed that individuals who have undergone catch-up growth are at a higher risk of developing the metabolic syndrome and type 2 diabetes compared to those who did not experience catch-up growth, although the exact underlying mechanisms are not fully understood. Catch-up growth after food restriction (CUGFR) is reportedly characterized by a significant change in food intake. Whether this fluctuation of food intake leads to the change in GLP-1 secretion and consequently alteration in the pancreatic islet function remains unclear. Therefore, the aim of this study was to examine the impact of CUGFR on the entero-insular axis and the possible mechanism underlying metabolic disorder.

\section{Methods}

\section{General Study design}

6-week-old male Sprague-Dawley rats (Center of Experimental Animals, Tongji Medical College, Huazhong University of Science and Technology, China), weighing 180$200 \mathrm{~g}$ and caged singly in wire bottomed cages in a temperature-controlled room $\left(22 \pm 1^{\circ} \mathrm{C}\right)$ with a 12 -h light/ dark cycle, were raised on a commercial pellet diet (Center of Experimental Animals, Tongji Medical College, Huazhong University of Science and Technology, China) consisting, by energy, of $22 \%$ protein, $66 \%$ carbohydrates, and $12 \%$ fat and had free access to tap water. Animals were maintained in accordance with regulations of the institute and guidelines for the care and use of laboratory animals. The experiments were conducted after 1-week adaptation to housing conditions. All protocols of animal treatment were approved by the institutional animal ethics committee.

\section{Animal model of catch-up growth}

7 -week-old rats $(n=36)$ were randomly divided into two groups (Figure 1): a normal chow group (NC group; $\mathrm{n}=$ 18 ) and a CUGFR group $(n=18)$. Rats in NC group were raised on a pellet diet ad libitum for 8 weeks and rats in CUGFR group were put on food restriction for 4 weeks at $60 \%$ of the diet intake of ad libitum-fed rats and then were re-fed with free access to pellet diet. Changes in food intake were determined once a day and body weight was measured every 7 days. Six rats in each group were sacrificed by decapitation 0 (the end of 4-week food restriction), 2 (catch-up growth for 2 weeks), and 4 (catch-up growth for 4 weeks) weeks after re-feeding.

\section{Oral glucose tolerance test}

Two days before decapitation, an oral glucose tolerance test (OGTT) was performed by orally administering 0.5 $\mathrm{g} / \mathrm{ml}$ glucose solution at $1 \mathrm{ml} / 100 \mathrm{~g}$ body weight $(5 \mathrm{~g} / \mathrm{kg})$. In brief, the tip of the tail of a $20 \mathrm{~h}$-fasted conscious rat was cut off and tail vein blood samples were taken, and then dextrose at $2 \mathrm{~g} / \mathrm{kg}$ body weight was given by gavage. Additional tail blood samples were then drawn from the conscious rats 15, 30 and 60 min after the gavage. Blood was collected with EP tube containing EDTA $(1 \mathrm{mg} / \mathrm{ml})$ and aprotinin $\left(5 \times 10^{5} \mathrm{kIU} / \mathrm{L}\right.$; Sigma, Oakville, ON, Canada) as previously reported by Reimer et al[12]. Diprotin A, an inhibitor of dipeptidyl peptidase IV was added to the blood sample at $34 \mu \mathrm{g} / \mathrm{ml}$ (Calbiochem, La Jolla, CA) to inhibit GLP-1 degradation. Blood was centrifuged at $1,600 \mathrm{~g}$ for $15 \mathrm{~min}$ at $4^{\circ} \mathrm{C}$ and plasma was stored at $-80^{\circ} \mathrm{C}$ for later radioimmunoassay.

\section{Determination of plasma glucose, insulin and GLP-1}

Plasma glucose was measured by employing a One Touch Basic blood glucose monitoring system (Lifescan Canada Ltd., Burnaby, British Columbia, Canada). Radioimmunoassay kits for insulin and active GLP-1 (7-36 amide) were obtained from Linco Research (St. Louis, MO, USA). For insulin determination, the sensitivity of the kit was < $17.22 \mathrm{pmol} / \mathrm{l}$ and intra-assay coefficient of variation was $<$ 9.4\% at $631.74 \mathrm{pmol} / \mathrm{l}$. For GLP-1 (7-36 amide) assays, sensitivity was $<3 \mathrm{pmol} / \mathrm{l}$ and intra-assay coefficient of variation was $<12 \%$ at $40 \mathrm{pmol} / \mathrm{l}$. Area under the curve (AUC), which reflects the area above baseline, was determined as reported by Massimino et al[13].

\section{Measurement of incretin effect}

Two experiements were carried out after an overnight fast (20 hours) at an interval of 2 days. In the first experiment, rats received a 1 -h OGTT ( $5 \mathrm{~g} / \mathrm{kg}$ body weight) with plasma glucose, insulin and GLP-1 concentrations measured $0,15,30$ and $60 \mathrm{~min}$ after gavage. With the second experiment, the plasma glucose profile was reproduced by a variable intravenous (IV) glucose $(20 \%$ dextrose) infusion and the infusion rate was adjusted to match the glucose concentrations during the OGTT. In this experiment, venous blood was sampled 0, 15, 30 and 60 min after the start of glucose infusion for plasma glucose and insulin determination by using aforementioned method. For each rat, the incretin effect was calculated from the insulin responses during the OGTT and matched intravenous glucose infusion using the following formula[14]: $100 \times\left(\right.$ Insulin $\mathrm{AUC}_{\mathrm{OGTT}^{-I n s u l i n} \mathrm{AUC}_{\mathrm{IV}} \text { glu- }}$ cose)/Insulin $\mathrm{AUC}_{\mathrm{OGTT}}$. This calculation eliminated the 


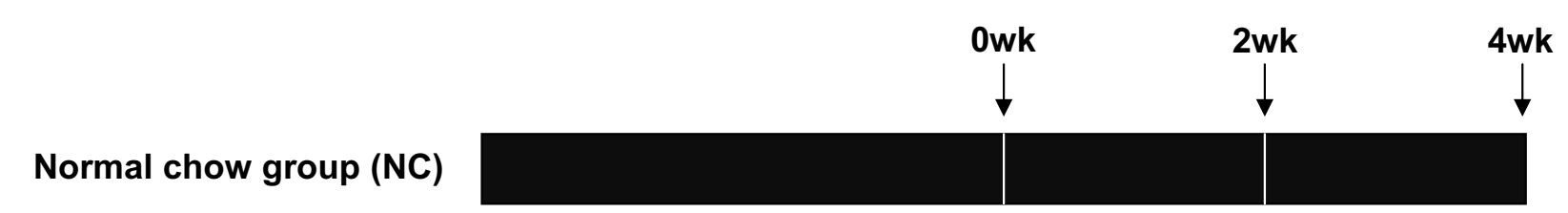
Catch-up growth after food restriction (CUGFR)

\section{Normal chow} Food restriction

Figure 1 The diagram of experiment design. Rats were divided into NC group $(n=18)$ and CUGFR group $(n=18)$. The arrows indicate the specific days on which rats were sacrificed.

impact of glucose levels per se, which were matched by design.

\section{Immunohistochemistry and morphometry}

Pancreata were resected, cleared of fat and spleen, weighed, fixed, and embedded in paraffin. 3- $\mu \mathrm{m}$ sections were deparaffinized and stained. Mouse anti-rat insulin polyclonal antibody (1:100; Boster Biotech Inc., Wuhan, China) was used for the immunofluorescence staining and tissues were processed as described[15]. Beta cell mass was morphometrically determined as described previously[16]. For negative controls, non-immune serum instead of primary antibody was used. Since we previously found that the effect of food-restriction on pancreatic islet size was greater in the head than in the tail of the pancreas (data not shown), for each animal, four representative sections of pancreas from the head region were selected for analysis.

Mucosal samples from ileum of rats were fixed in $10 \%$ buffered formalin and paraffin-embedded. Sections for histological evaluation were obtained from tissue blocks cut perpendicular to the mucosal surface, and stained with haematoxylin and eosin. Images were recorded on a digital camera (Coolpix 950, Nikon, Japan) and an Image Pro Plus software package (Media Cybernetics, Bethesda, MD, USA) was used to measure the height of 10 villi and the depth of 10 crypts in each section on randomlyselected microscopic fields [17]. The glucagon antiserum (1:100; Boster Biotech Inc., Wuhan, China) is a polyclonal antiserum which can react against enteroendocrine $\mathrm{L}$ cells[18]. For immunohistochemistry, tissues were processed and L cell size was calculated by morphometric analysis as previously described[19].

\section{RT-PCR and quantitative real-time PCR}

The bile ducts of anesthetized rats were cannulated with a 27-gauge needle, and the pancreas was distended with a solution containing $2 \mathrm{mg} / \mathrm{ml}$ collagenase. Each pancreas was then incubated in a tissue culture flask at $37^{\circ} \mathrm{C}$ and the islets isolated according to the method reported by Gotoh et al [20]. Total RNA was extracted from the islets by using Simply P total RNA extraction kit (BioFlux, Hangzhou, China). Reverse transcription was performed with $1 \mu \mathrm{g}$ of total RNA as sample material and oligo $(\mathrm{dT})_{20}$ as a primer by using the first strand cDNA synthesis kit (Toyobo Co., Ltd., Osaka, Japan). The resultant cDNA was amplified using primers (synthesized by Sangon Inc. Shanghai, China), and PCR reaction was performed in a thermal cycle. Expression of the glucagons-like peptide-1 receptor (GLP-1R) gene was first detected by RT$\operatorname{PCR}[21,22]$, and then real-time quantitative PCR was performed using the following profile. Primer sequences for rat GLP-1R were: 5'-GCTGGACCAGGAACTCCAACA-3' (forward) and 5'-ATGCAGATGAC CCGGATGAAG-3' (reverse). The primer sequences for beta actin gene were 5'-CGTTGACATCC GTAAAGAC-3' (forward) and 5'-TGGAAGGTGGACAGTGAG-3' (reverse). The two-step real-time quantitative PCR was done by using the SYBR Premix ExTaq (TaKaRa Biotechnology Co. Ltd., Dalian, China) and was heated at $95^{\circ} \mathrm{C}$ for a minimum time of $30 \mathrm{~s}$, then 40 cycles at $95^{\circ} \mathrm{C}$ for $15 \mathrm{~s}$ and $60^{\circ} \mathrm{C}$ for $45 \mathrm{~s}$ in a DNA iCycler apparatus (BIO-RAD, Mississauga, ON, Canada). Results were presented as the relative expression level, which were fold ratio to the $\mathrm{NCO}$ group (set to 1 ).

\section{Statistical analysis}

Data analyses were performed by employing SPSS 13.0 statistical software package (SPSS, Chicago, IL, USA). Data were expressed as means \pm SD. Differences between the groups were evaluated by using independent t-test, and considered as statistically significant at $\mathrm{p}<0.05$.

\section{Results}

\section{Food intake and body weight}

Rats in CUGFR group were fed with only $60 \%$ of the diet intake of ad libitum-fed rats (normal intake) during food restriction. Our previous study showed that the body 


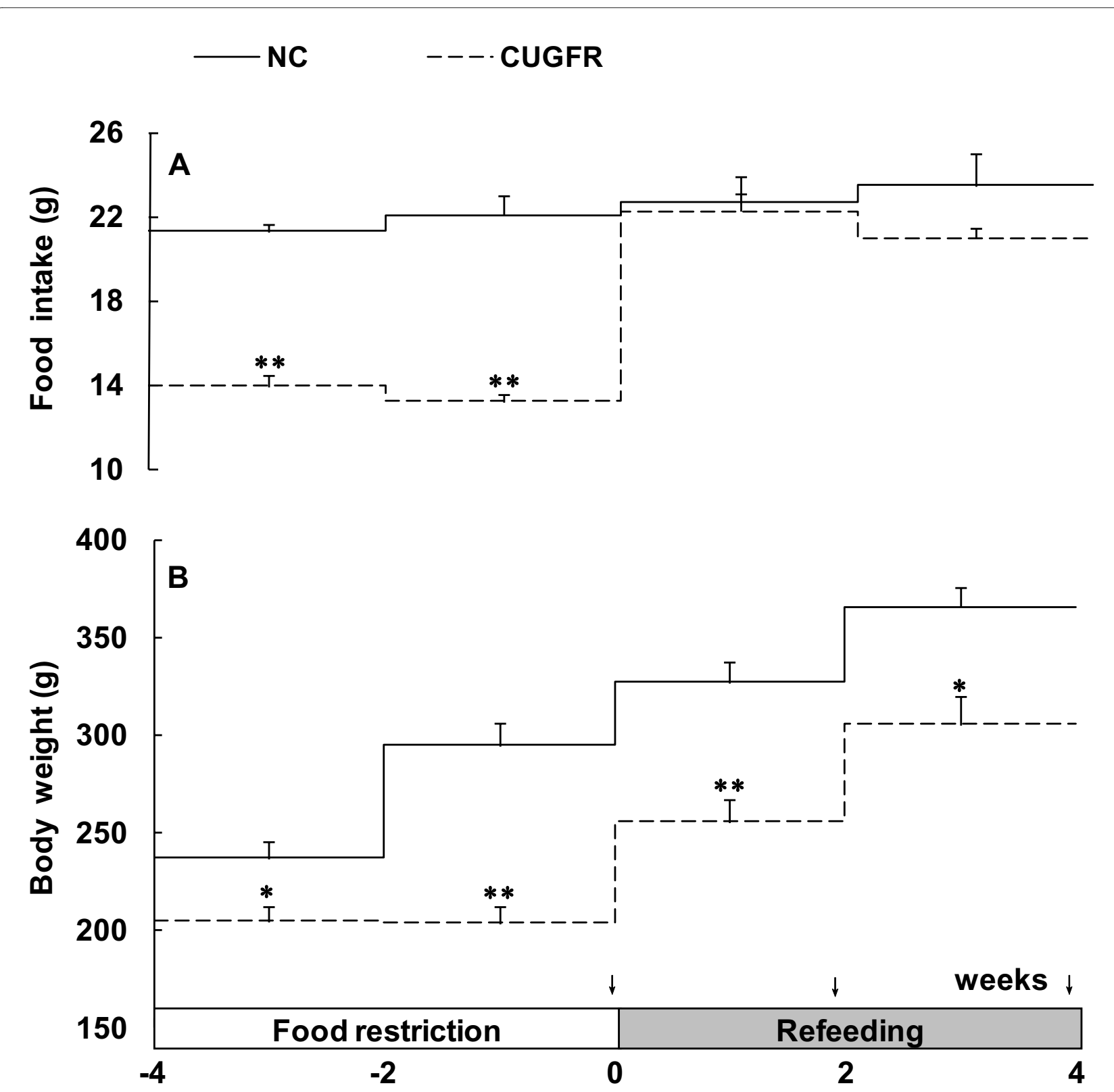

Figure 2 Food intake and body weight during food restriction and re-feeding stage. All values are expressed as $m e a n s \pm S D(n=6)$. ${ }^{*} P \leq 0.05$ versus NC group; ${ }^{* *} \mathrm{P} \leq 0.01$ versus NC group. The arrows indicate the specific days on which oral glucose tolerance tests (OGTTs) were performed.

weight of the rats remained roughly the same during the whole restriction period. However, decreased body weight and malnutrition resulted if they were fed with less than $60 \%$ of the normal intake (data not shown). After re-feeding, the food intake in CUGFR group increased rapidly in the first 2 weeks to reach virtually the same level as that of the control group (Figure 2-A). The body weight of these rats, however, was consistently lower than that of the control group, even four weeks after the re-feeding (Figure 2-B).

\section{Beta cell mass and function}

$\mathrm{HE}$ and insulin fluorescence staining (Figure 3, 4) exhibited that the relative area and mass of beta cells were significantly less in CUGFR group than in NC group during food-restriction. After re-feeding, the relative area and mass of beta cells increased gradually over time, but they failed to return to level of the controls even 4 weeks after the catch-up growth.

Plasma glucose and insulin levels at the conclusion of food-restriction session were slightly lower than or simi- 


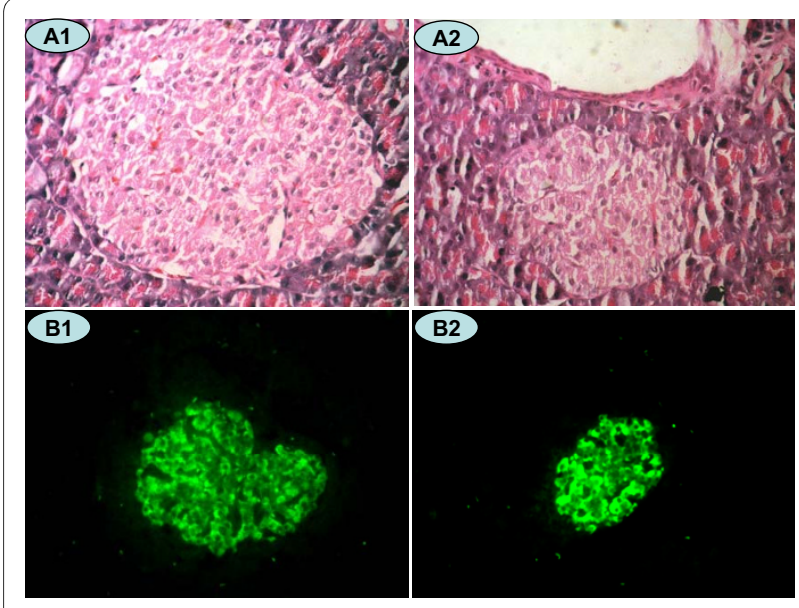

Figure 3 HE Staining ( $\times 400$ magnification) and insulin immunofluorescence staining ( $\times \mathbf{2 0 0}$ magnification) in a rat pancreatic islet. Islet cells in the NC (A1 and B1) and CUGFR (A2 and B2) groups 4 weeks after catch-up growth with $\mathrm{HE}$ staining (A1 and $\mathrm{A} 2$ ) and insulin fluorescence staining (B1 and B2). Green fluorescence shows cells positive for insulin.

lar to those of $\mathrm{NC}$ group $0,15,30$ and 60 min after glucose gavage (Figure 5-A1, B1). Two weeks after the catchup growth, plasma glucose remained lower in CUGFR group than in the NC group (Figure 5-A2) whereas plasma insulin was higher than that of controls $15 \mathrm{~min}$ after the gavage (Figure 5-B2). Four weeks after the catchup, plasma glucose was still lower in CUGFR group than in NC group. However, plasma insulin levels were higher than those of controls at all time points of OGTT, especially $30 \mathrm{~min}$ after the gavage (Figure 5-A3, 5-B3).
Plasma GLP-1 concentration and GLP-1R mRNA expression in islets

Food-restriction resulted in a significant decrease in plasma GLP-1 level. Following re-feeding, GLP-1 increased but did not arrive at the level of NC group even 4 weeks after the catch-up (Figure 5-C).

As expected, electrophoresis of RT-PCR products of the pancreatic GLP-1 receptor yielded a single band (Figure 6-A1). A control PCR run with no pancreatic islet RNA or no primers yielded no product. Identity of every distinct band was confirmed by direct sequencing (data not shown). Expression levels of the GLP-1 receptor gene were compared between NC and CUGFR groups 0, 2 and 4 weeks after the catch-up growth. GLP-1R expression ratio increased significantly in the CUGFR group during food restriction. However, catch-up growth blunted this trend, and GLP-1R expression ratio declined with time and was even lower than that of NC group after 4-week catch-up growth (Figure 6-A2).

\section{Incretin effect}

The glucose concentrations were well matched between the OGTT and isoglycemic IV glucose test (IsoG IVGT) in all groups (Figure 7 A1-A3). However, the insulin response was greater after oral than intravenous glucose before or after re-feeding, which has been generally known as "incretin effect" (Figure 7 B1-B3). The incretin effect was decreased significantly after food restriction compared with NC group. After re-feeding, the incretin effect remained consistently lower in the re-feeding group till the end of the study (Figure 8).

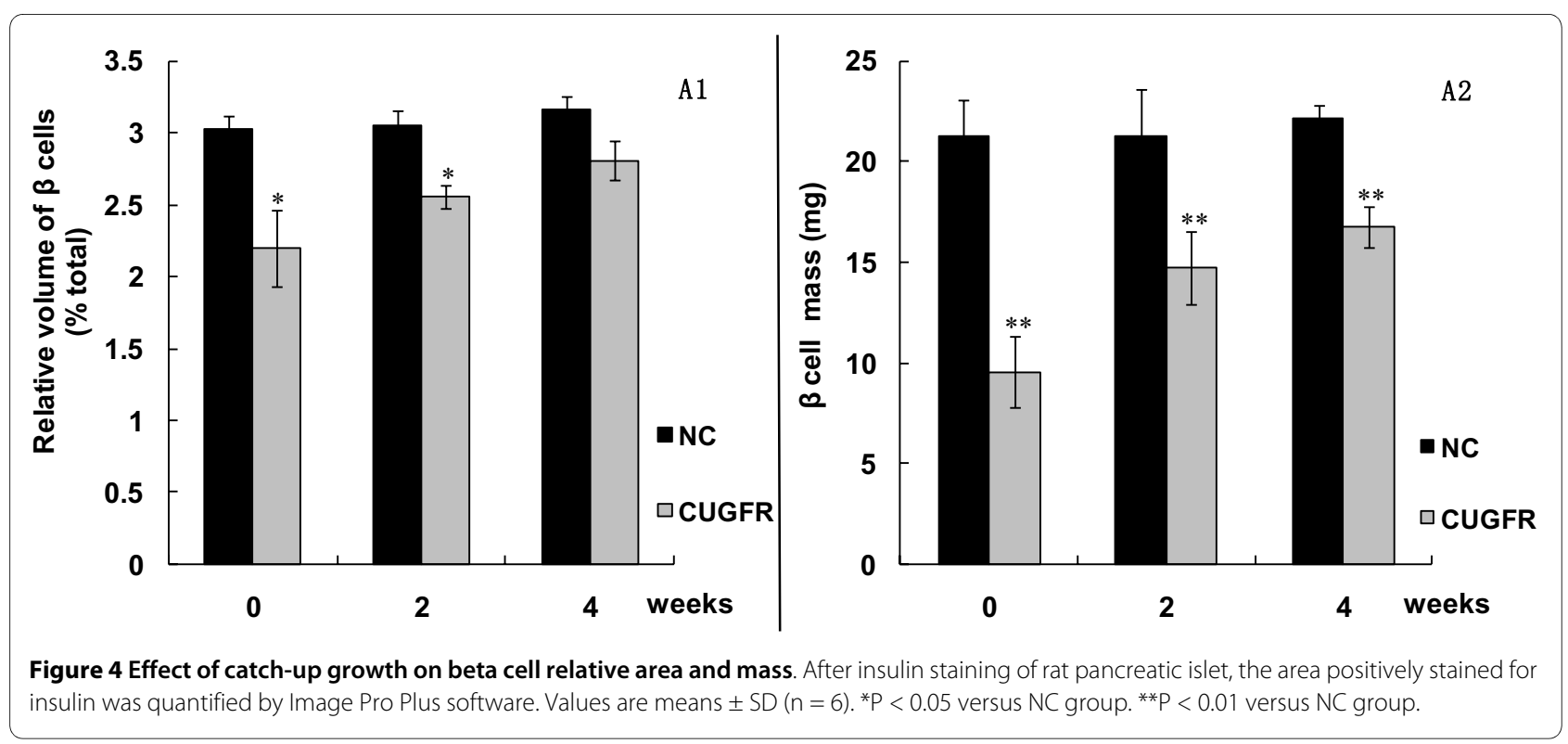




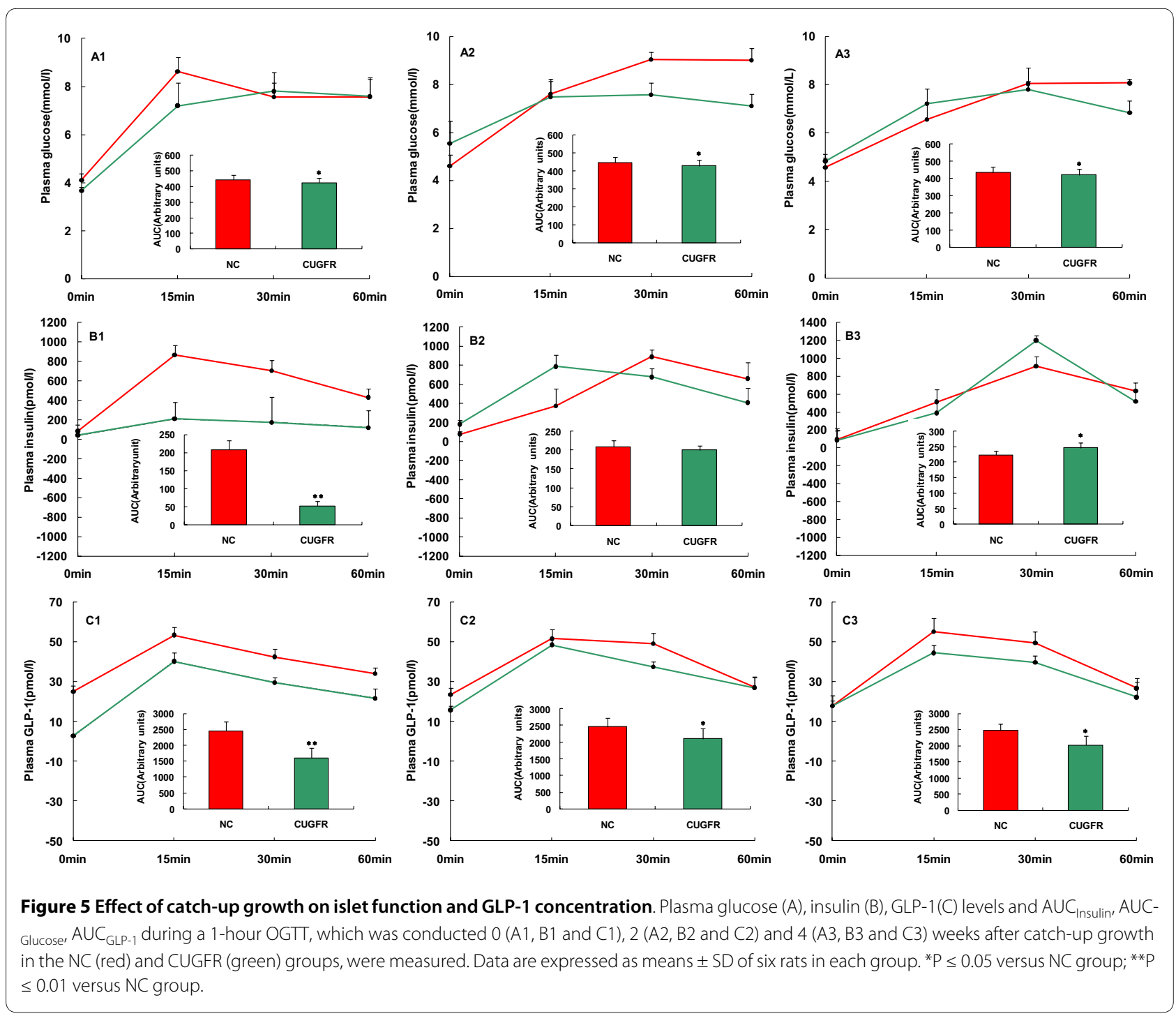

\section{The morphology of intestinal mucosa and number of} glucagon-positive cells in the ileum

The morphological measurements of the rat's ileum mucosa are presented in Figure 9A and Table 1. Both villus height and villus height-to-crypt depth ratio decreased during food restriction. However, catch-up growth increased villus height and decreased the crypt depth, thereby resulting in a villus height to crypt depth ratio higher than that of NC group. Nevertheless, this trend weakened over the time of catch-up growth.

Figure 9B and Figure 10 show that there were fewer glucagon-positive cells in CUGFR group than in NC group at the end of food restriction. Although catch-up growth partially moderated this trend, the number of glucagonpositive cells in CUGFR group failed to catch up with those of NC group even 4 weeks after the catch-up growth.

\section{Discussion}

The importance of gut-endocrine pancreas interaction on glucose metabolism was first recognized by Claude Bernard about a century ago[23] and further conceptualized by Zunz and La Barre who introduced the term "incretins", which describe a family of hypoglycemic factors found in the extract of duodenum[24]. On the basis of understanding of the influence of the gut on pancreatic islet functions, in 1969, Unger and Eisentraut integrated these notions under a single concept of "entero-insular axis"[25]. The entero-insular axis represents a network of neural and endocrine communications between the alimentary tract and the pancreatic islets, which promotes insulin release in response to feeding. Although approximately $30 \%$ of the oral glucose-induced insulin secretory effect was accounted for by GIP, Bell and colleagues predicted the existence of GLP-1 based on their studies of 


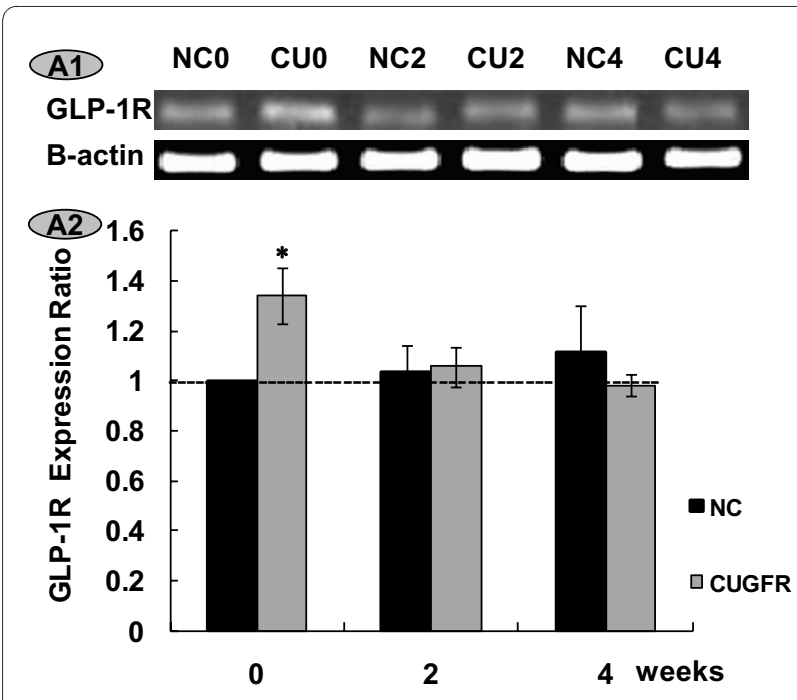

Figure 6 Effect of catch-up growth on GLP-1R mRNA expression in islets. A1. RT-PCR products from RNA extracted from rat ( $n=5-6$ per group) pancreatic islets. The beta actin control was comparable in all groups. A2. The statistical results of real time quantitative PCR products from RNA extracted from rat pancreatic islets. Data are expressed as means $\pm S D$. ${ }^{*} P \leq 0.05$ versus $N C$ group.

the proglucagon gene[26] and subsequent investigations confirmed that GLP-1 is the most important post-prandial hormone responsible for insulin secretion[27,28].

Catch-up growth falls into two types in terms of age[2]. Early catch-up growth refers to children who are born small but catch up in weight and height in infancy or early childhood. Late catch-up growth affects children who may or may not be born small, but become stunted in infancy, childhood or adulthood and catch up later in weight, becoming "stunted-obese". The latter is more commonly seen, as it can happen in many cases, such as rapid economic development in developing countries, migration from rural to urban settings, war, famine, rehabilitation from chronic diseases, yo-yo phenomenon (weight suppression by low caloric diet, and weight rebound later), and so on[29,30]. It has been suggested that late catch-up growth may be associated with the development of type 2 diabetes and other metabolic diseases. In order to simulate the effects of late catch-up growth in human adults, the most prevalent form in developing countries, our study was conducted in mature rats and late catch-up growth was observed at different time points $(0,2,4$ weeks after re-feeding), with an attempt to examine the impact of catch-up growth on the entero-insular axis over time.

In this study, food intake and body weight of the rats as well as insulin secretion increased markedly 2 weeks after re-feeding, suggesting that catch-up growth started. Although the number of L cells and GLP-1 concentration increased at that time, the incretin effect did not parallel the increase in GLP-1, which might be ascribed to the decrease in GLP-1R. Food intake, body weight, beta cell mass and insulin concentration increased with the time of catch-up growth. On the other hand, L cell number and GLP-1 did not increase correspondingly, resulting in no increase in the incretin effect. It seems that the catchup in the incretin effect lags far behind catch-up in food intake and body weight, which might be an important mechanism by which catch-up growth leads to metabolic disorder.

The metabolic syndrome may occur in both types of catch-up growth and most studies on the mechanisms of catch-up growth had focused on insulin resistance[31]. Although some evidence $[32,33]$ suggests that pancreatic islet dysfunction can result from early catch-up growth, so far whether late catch-up growth also affects the beta cells has not been studied. In this study, although beta cell functions remained fundamentally normal 4 weeks after catch-up growth, in view of the lowered incretin effect and the diminished islet size, the pancreatic islets would, presumably, eventually be unable to maintain insulin secretion if the blood glucose increased excessively and rapidly over the time of catch-up growth. The question will arise as to whether in the long run this beta cell dysfunction will lead to the development of diabetes. This issue is beyond the scope of this study and will be investigated in our later studies.

This study was designed to verify whether or not the fluctuation of food intake during CUGFR leads to the change in GLP-1 secretion and thereby affects the beta cell function. Therefore, we examined the pancreatic islet size, insulin concentration and plasma GLP-1 concentration during CUGFR. Our results showed that pancreatic islet size was diminished, insulin concentration was lowered, and plasma GLP-1 concentration and incretin effect were significantly decreased at the end of the 4-week food restriction period. After 4-week catch-up growth, although both insulin and GLP-1 concentration in CUGFR group were increased, the plasma GLP-1 level still did not match that of the control group. Recent epidemiological and clinical studies demonstrated that individuals experiencing catch-up growth are more at risk of developing central obesity, glucose intolerance, type 2 diabetes mellitus and cardiovascular diseases, which are all encompassed in the definition of metabolic syndrome[30]. We believe that the changes in GLP-1 concentration and islet function play a vital role in the development of above-mentioned conditions. In accordance with our inference, Stoffers [34] was intrigued by the potential for GLP-1 agonist administration during the pre-diabetic period to ameliorate or prevent the later onset of diabetes. They used a surgical model of intrauterine growth retardation(IUGR) in which bilateral uter- 

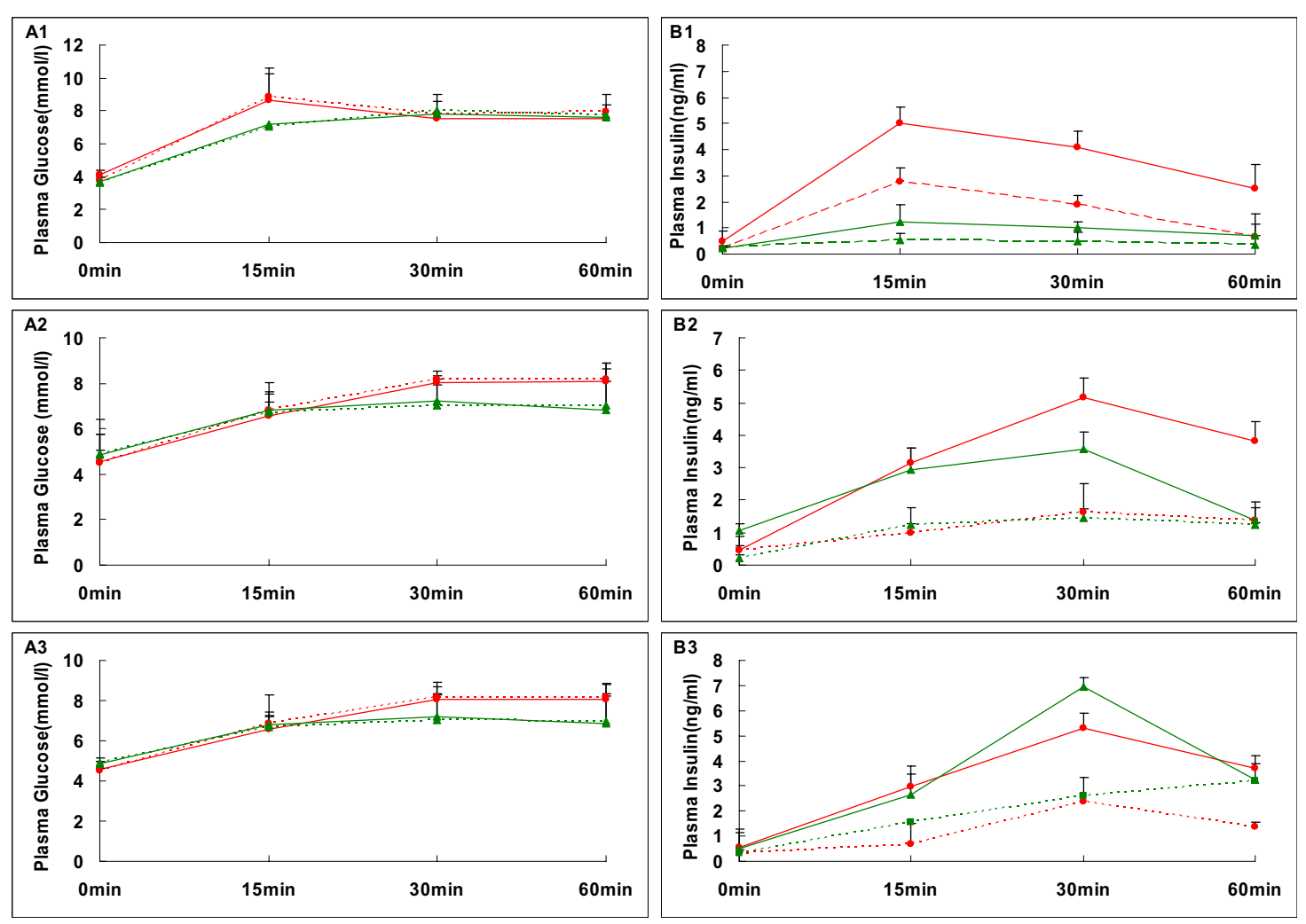

Figure 7 Time course of the glucose and insulin following oral and IV glucose in the normal and catch-up growth rats. Plasma glucose (A1, $A 2, A 3)$ and insulin (B1, B2, B3) concentrations in rats of NC group (red) or CUGFR group (green) during oral glucose tolerance test (solid line) and intravenous glucose infusion test (broken lines) designed to match the oral glucose curve in six rats, were detected after catch up growth for 0 (A1, B1), $2(A 2, B 2)$ and $4(A 3, B 3)$ weeks. Data are expressed as means $\pm S D$.

ine artery ligation is carried out on the rat gestation day 19 and found that, at 3 months of age, all vehicle treated IUGR rats developed overt diabetes in association with a $90 \%$ decrease in beta cell mass. However, exenatide -4treated IUGR rats maintained a normal beta cell mass and normal glucose tolerance. The normalization of

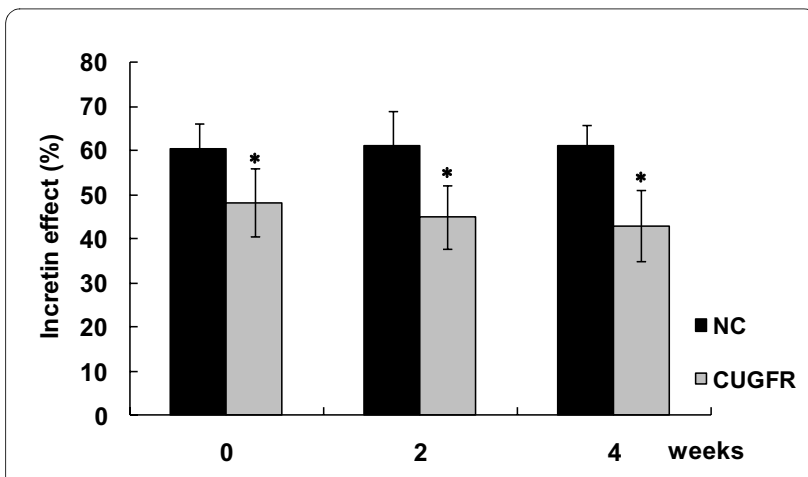

Figure 8 Effect of catch-up growth on the incretin effect. Data are expressed as means \pm SD. The incretin effect was calculated by comparing the insulin response to oral and matched IV glucose load. ${ }^{*} P \leq$ 0.05 versus $N C$ group. blood glucose was maintained beyond 8 months of age and appeared to represent a lifelong prevention of diabetes.

Since GLP-1R, a G-protein-coupled receptor, selectively locates on the beta cells[35] to serve as a regulator of pancreatic islet mass and function, we examined the GLP-1R mRNA expression in the process of catch-up growth. We observed an increase in GLP-1R expression ratio during the food restriction period, which, together with the decrease in glucose and GLP-1 concentration, suggests that a negative feedback mechanism exists between GLP-1 and GLP-1R. This notion is consistent with the speculation put forward by Abraham et al[36] who speculated that the expression of the GLP-1R coupled with the expression of proglucagon and resultant GLP-1 may establish an autocrine/paracrine hormonal feedback loop that is important for some physiological functions.

GLP-1 is released from L cells of the intestines[37]. However, whether GLP-1 secretion is related to the change in the number of L-cells during CUGFR is not clear. Hence, in this study we further investigated the intestinal morphology and the change in L cell number. 


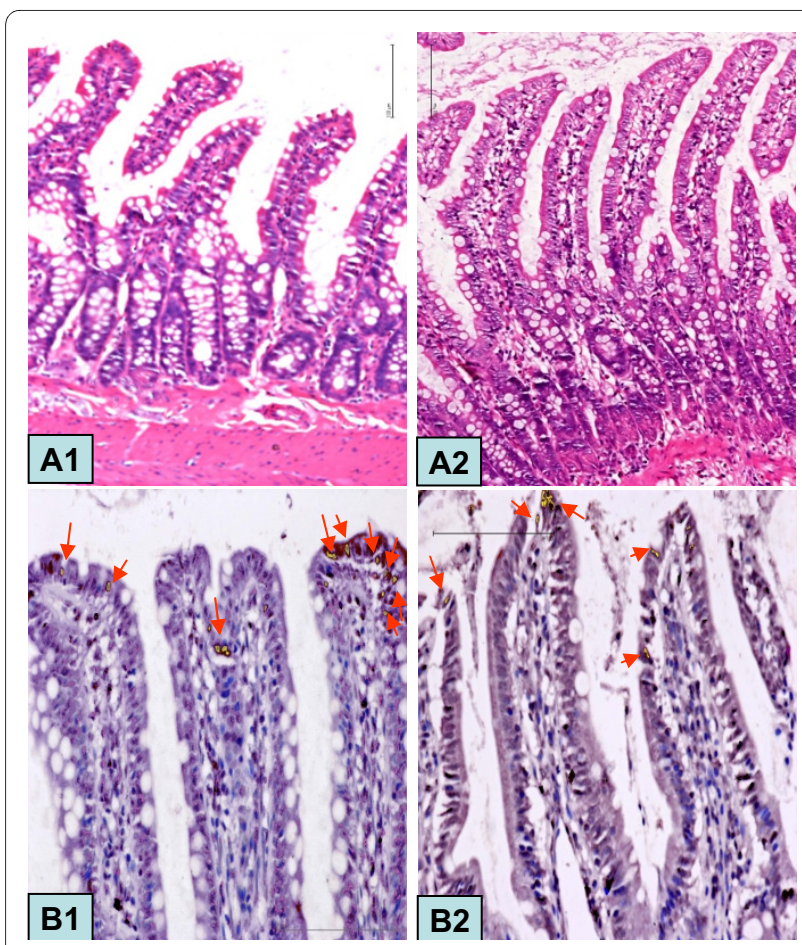

Figure 9 HE Staining ( $\times 200$ magnification) and glucagon staining ( $\times \mathbf{4 0 0}$ magnification) in rat ileum. Ileal villus observed in the CUGFRO (A1) and CUGFR2 (A2) groups with HE staining and NC4 (B1) and CUGFR4 (B2) groups with glucagon staining. Arrow shows a glucagonpositive cell.

Some studies examined the relationship between food restriction and gastrointestinal function and demonstrated that the growth, function, and repair of gut mucosa are highly dependent on nutrient availability, and that nutritional status is associated with expression of various endogenous intestinal growth factors[38]. In line with these findings, our study showed that food restriction reduced villus height and crypt depth, resulting in fewer $\mathrm{L}$ cells and inevitably leading to lower plasma GLP1 concentration and decreased incretin effect. When refeeding starts, the increase in the gastrointestinal load motivates gut mucosal growth. The most urgent task for

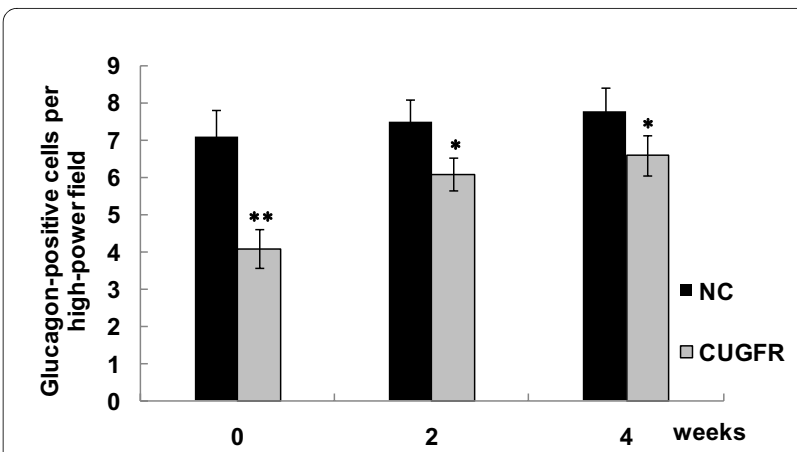

Figure 10 Effect of catch-up growth on glucagon-positive cells per high-power field. To quantify the expression of glucagon, an average of 50 sections of rat ileum from each of two animals were examined. The number of cells immunoreactive for glucagon was determined. Data are expressed as means $\pm S D$. ${ }^{*} P \leq 0.05$ versus NC group; ${ }^{* * P} \leq 0.01$ versus NC group

the body then is to create more intestinal villi so as to absorb and transport more nutrients instead of creating more L cells. Cani et al[19] hypothesize that L-cells, like other intestinal cells, come from common stem cells. Therefore, we can postulate that, since stem cells are available in limited amounts, the formation of $\mathrm{L}$ cells will be inadequate, resulting in insufficient GLP-1 concentration and weaker incretin effect even after re-feeding. However, the exact mechanisms warrant further study.

\section{Conclusion}

Although no diabetes was observed during our study, there existed obvious secretory defects of GLP-1 and weaker incretin effect in our murine model during a 4week catch-up growth period after food restriction, demonstrating that catch-up growth could impair enteroinsular axis due to disturbed $\mathrm{L}$ cell formation. The detailed mechanisms remain unclear and the subsequent development of diabetes cannot be predicted at present. Therefore, further studies are needed to establish the link between the catch-up growth-related change in the entero-insular axis and diabetes mellitus.

Table 1: Effects of catch-up growth on the morphology of the intestinal mucosa in rat ileum.

\begin{tabular}{llll}
\hline Items & Villus height $(\boldsymbol{\mu m})$ & Crypt depth $(\boldsymbol{\mu m})$ & Villus height:crypt depth \\
\hline NC0 & $260 \pm 26$ & $116 \pm 13$ & $2.24 \pm 0.12$ \\
NC2 & $268 \pm 20$ & $123 \pm 21$ & $2.18 \pm 0.53$ \\
NC4 & $264 \pm 24$ & $128 \pm 21$ & $2.06 \pm 0.41$ \\
CU0 & $204 \pm 26^{\mathrm{b}}$ & $111 \pm 16$ & $1.84 \pm 0.63^{\mathrm{b}}$ \\
CU2 & $302 \pm 15^{\mathrm{a}}$ & $95 \pm 22^{\mathrm{b}}$ & $3.18 \pm 0.92^{\mathrm{b}}$ \\
CU4 & $284 \pm 25$ & $102 \pm 19^{\mathrm{a}}$ & $2.78 \pm 0.45^{\mathrm{a}}$ \\
\hline
\end{tabular}

Data are expressed as means \pm SD. a $\mathrm{P} \leq 0.05$ versus NC group; $\mathrm{b} \mathrm{P} \leq 0.01$ versus NC group. 


\section{Competing interests}

The authors declare that they have no competing interests.

\section{Authors' contributions}

LLC and WHY were responsible for the design and overall performance of the study as well as data analysis and preparation of the manuscript. JZ, XH, WK and $\mathrm{HHZ}$ were all involved in the design of this study. All authors read and approved the final manuscript.

\section{Acknowledgements}

This work was supported by a grant from the National Natural Science Foundation of China (No. 30771035). The authors are especially indebted to Dr. XiangFei Guo for his assistance in animal care. We also thank Dr. Payal Buckoreelall for her help in the manuscript preparation.

\section{Author Details}

Department of Endocrinology, Union Hospital, Tongji Medical College, Huazhong University of Science and Technology, Wuhan 430022, China

Received: 22 February 2010 Accepted: 26 May 2010

Published: 26 May 2010

\section{References}

1. Prader A, Tanner JM, von Harnack GA: Catch-up growth following illness or starvation. Pediatrics 1963, 62:646-659.

2. Victora CG, Barros FC: The catch-up dilemma: relevance of Leitch's 'lowhigh' pig to child growth in developing countries. Int J Epidemiol 2001 30:217-220

3. Dulloo AG: Thrifty energy metabolism in catch-up growth trajectories to insulin and leptin resistance. Best Pract Res Clin Endocrinol Metab 2008, 22(1):155-171.

4. Hales CN, Barker DJ, Clark PM, Cox LJ, Fall C, Osmond C, Winter PD: Fetal and infant growth and impaired glucose tolerance at age 64. Br Med J 1991, 303:1019-1022.

5. Phillips DI, Barker DJ, Hales CN, Hirst S, Osmond C: Thinness at birth and insulin resistance in adult life. Diabetologia 1994, 37:150-154.

6. Cettour P, Samec S, Russell AP, Summermatter S, Mainieri D, CarrilloTheander C, Montani JP, Seydoux J, Rohner-Jeanrenaud F, Dulloo AG: Redistribution of glucose from skeletal muscle to adipose tissue during catch-up fat: A link between catch-up growth and later metabolic syndrome. Diabetes 2005, 54:751-756.

7. Curi R, Hell NS: Metabolic changes of twenty weeks food-restriction schedule in rats. Physiol Behav 1986, 36:239-243.

8. Morgan LM: Insulin secretion and the entero-insular axis. In Nutrient regulation of insulin secretion Edited by: Flatt PR. The Biochemical Society, Portland Press; 1992.

9. Fehmann HC, Goke R, Goke B: Cell and molecular biology of the incretin hormones glucagon-like peptide- 1 and glucose-dependent insulinotropic polypeptide. Endocr Rev 1995, 16:390-410.

10. Baggio LL, Drucker DJ: Biology of incretins: GLP-1 and GIP. Gastroenterology 2007, 132:2131-2157.

11. Burcelin R: The incretin: a link between nutrients and well-being. $\mathrm{Br} J$ Nutr 2005, 93:S147-S156.

12. Reimer RA, Russel JC: Glucose tolerance, lipids, and GLP-1 secretion in JCR:LA-cp rats fed a high protein fiber diet. Obesity 2008, 16(1):40-46.

13. Massimino S, McBurney MI, Field CJ, Thomson AB, Keelan M, Hayek MG, Sunvold GD: Fermentable dietary fiber increases GLP-1 secretion and improves glucose homeostasis despite intestinal glucose transport capacity in healthy dogs. J Nutr 1998, 128:1786-1793.

14. Nauck MA, Homberger E, Siegel EG, Allen RC, Eaton RP, Ebert R, Creutzfeldt W: Incretin effects of increasing glucose loads in man calculated from venous insulin and C-peptide responses. J Clin Endocrinol Metab 1986, 63:492-498.

15. Jackerott M, Møldrup A, Thams P, Galsgaard ED, Knudsen J, Lee YC, Nielsen JH: STAT5 activity in pancreatic beta-cells influences the severity of diabetes. Diabetes 2006, 55:2705-2712.

16. Bertin E, Gangnerau MN, Bellon G, Bailbé D, Arbelot De Vacqueur A, Portha $B$ : Development of beta-cell mass in fetuses of rats deprived of protein and/or energy in last trimester of pregnancy. Am J Physiol Regul Integr Comp Physiol 2002, 283:R623-R630.

17. Mitjans M, Ferrer R: Morphometric study of the guinea pig small intestine during development. Microsc Res Tech 2004, 63:206-214.
18. Drucker DJ, Asa S: Glucagon gene expression in vertebrate brain. J Bio/ Chem 1988, 263:13475-13478.

19. Cani P, Hoste S, Guiot Y, Delzenne NM: Dietary non-digestible carbohydrates promote L-cell differentiation in the proximal colon of rats. BrJ Nutr 2007, 98:32-37.

20. Gotoh M, Maki T, Satomi S, Porter J, Bonner-Weir S, O'Hara CJ, Monaco AP: Reproducible high yield of rat islets by stationary in vitro digestion following pancreatic ductal or portal venous collagenase injection. Transplantation 1987, 43:725-730.

21. Kulkarni RN, Bruning JC, Winnay JN, Postic C, Magnuson MA, Kahn CR: Tissue-specific knockout of the insulin receptor in pancreatic beta cells creates an insulin secretory defect similar to that in type 2 diabetes. Cell 1999, 96:329-339.

22. Kulkarni RN, Holzenberger M, Shih DQ, Ozcan U, Stoffel M, Magnuson MA, Kahn CR: Beta-cell-specific deletion of the Igf1 receptor leads to hyperinsulinemia and glucose intolerance but does not alter beta-cell mass. Nat Genet 2002, 31:111-115.

23. Bernard Claude: Memoire sur le pancreas. Bailliere, Paris, France: 1856

24. Zunz E, La Barre J: Contributions a l'etude des variations physiologiques de la secretion interne du pancreas. relations entre les secretions externe et interne du pancreas. Arch Int Physiol Biochim 1929, 31:20-44

25. Unger RH, Eisentraut AM: Entero-insular axis. Arch Intern Med 1969, 123:261-266.

26. Bell GI, Santerre RF, Mullenbach GT: Hamster preproglucagon contains the sequence of glucagon and two related peptides. Nature 1983 302:716-718.

27. Holst JJ, Orskov C, Nielsen OV, Schwartz TW: Truncated glucagon-like peptide 1 , an insulin releasing hormone from the distal gut. FEBS Lett 1987, 211:169-174.

28. Nauck M, Schmidt WE, Ebert R, Strietzel J, Cantor P, Hoffmann G, Creutzfeldt W: Insulinotropic properties of synthetic human gastric inhibitory polypeptide in man: interactions with glucose, phenylalanine, and cholecystokinin-8. J Clin Endocrinol Metab 1989, 69:654-662.

29. Schroeder DG, Martorell R, Flores R: Infant and child growth and fatness and fat distribution in Guatemalan adults. Am J Epidemiol 1999, 149:177-185.

30. Roseboom TJ, Meulen JHP van der, Ravelli ACJ, Osmond C, Barker DJP, Bleker OP: Effects of prenatal exposure to the Dutch famine on adult disease in later life: an overview. Mol Cell Endocrinol 2001, 185:93-98.

31. Chen LL: Catch-up growth--a new territory for understanding insulin resistance. Chin J Endocrinol Metab 2008, 24:235-238.

32. Crowther NJ, Cameron N, Trusler J, Toman M, Norris SA, Gray IP: Influence of catch-up growth on glucose tolerance and beta cell function in 7year-old children: results from the birth to twenty study. Pediatrics 2008, 121:e1715-e1722.

33. Jimenez Chillaron JC, Hernandez Valencia M, Reamer C, Fisher S, Joszi A, Hirshman M, Oge A, Walrond S, Przybyla R, Boozer C, Goodyear L, Patti ME: Beta-cell secretory dysfunction in the pathogenesis of low birth weight-associated diabetes: a murine model. Diabetes 2005, 54:702-711.

34. Stoffers DA: The development of beta-cell mass: recent progress and potential role of GLP-1. Horm Metab Res 2004, 36:811-821.

35. Tornehave D, Kristensen P, Romer J, Knudsen LB, Heller RS: Expression of the GLP-1 Receptor in Mouse, Rat, and Human Pancreas. J Histochem Cytochem 2008, 56:841-851.

36. Abraham EJ, Leech CA, Lin JC, Zulewski H, Habener JF: Insulinotropic hormone glucagon-like peptide- 1 differentiation of human pancreatic islet-derived progenitor cells into insulin-producing cells. Endocrinology 2002, 143:3152-3161.

37. Mortensen K, Christensen LL, Holst JJ, Orskov C: GLP-1 and GIP are colocalized in a subset of endocrine cells in the small intestine. Regul Pept 2003, 114:189-196.

38. Fernandez-Estivariz C, Gu LH, Gu L, Jonas CR, Wallace TM, Pascal RR, Devaney KL, Farrell CL, Jones DP, Podolsky DK, Ziegler TR: Trefoil peptide expression and goblet cell number in rat intestine: effects of KGF and fasting-refeeding. Am J Physiol Regul Integr Comp Physiol 2003, 284:R564-R573.

doi: $10.1186 / 1743-7075-7-45$

Cite this article as: Chen et al., Effect of catch-up growth after food restriction on the entero-insular axis in rats Nutrition \& Metabolism 2010, 7:45 